\title{
Voting characteristics of individuals with traumatic brain injury
}

\section{Mark A. Hirsch, Martha E. Kropf, Flora M. Hammond, Lisa Schur, Jason H. Karlawish, and Andrew M. Ball}

Background: Voting is the foundation of democracy. Limited data exist about voting characteristics of individuals with neurologic impairment including those living with a traumatic brain injury (TBI). Aim: To statistically examine voting characteristics using a convenience sample of registered voters with TBI during elections held in Mecklenburg County, North Carolina - 2007, 2008. Method: Data were collected on 51 participants with TBI during May 2007, 2008 general, and 2008 Presidential Election. Results: 1) there was a significant difference between the Competence Assessment Tool for Voting (CAT-V) total score of participants with TBI who voted and the CAT-V total score of participants with TBI who did not vote and the CAT-V total score predicted voting, 2) the age of the participants with TBI was predictive of voting, and 3) being married was inversely related to voting. Conclusion: We find that there is variation in voting even among this small sample interviewed for the present study, and that the variation is predictable. Those with the highest CAT-Vs are most likely to vote. In addition, we find that traditional predictors of voting simply aren't predictors among this TBI group, and even one, whether the person is married, has a negative effect on voting.

KEY WORDS: Traumatic Brain Injury, Political participation, Voting

\section{Introduction}

Voting is a fundamental aspect of any democracy and one of the most basic forms of political participation. Although it is known that relative to other chronic health conditions, neurodegenerative brain diseases have among the strongest of negative association with voter turnout (Sund et al. 2017), only four studies that we know of have examined voting among individuals with cognitive impairment, and no data exist concerning the voting characteristics of individuals with traumatic brain injury (TBI). Research suggests that those with self-reported "cognitive impairments" were less likely to vote in recent elections (2008 and 2010) than those without disabilities (Schur, Adya, and Kruse 2013; Schur and Adya 2012). The Schur Adya and Kruse study (2013) analyzed the Census Bureau's Current Population Survey, where "cognitive impairments" was operationalized with the question, "Because of a physical, mental, or emotional condition, does anyone have serious difficulty concentrating, remembering, or making decisions?" Schur and her colleagues give us a broad picture of the voting life of people with cognitive impairments, and Sund and colleagues (2017) conclude that individuals with neurodegenerative conditions are among the least likely to vote, when compared with individuals with any other chronic health conditions. Scholars are in the initial phases of defining voter participation characteristics within each neurodegenerative condition subgroup such as people living with Alzheimer's disease/cognitive impairment (Appelbaum, Bonnie, and Karlawish 2005; De Cauwer 2005; Karlawish et al. 2002; Karlawish et al. 2008; Karlawish 2008), mental illness/schizophrenia (Agran, MacLean, and Kitchen 2016; Doron et al. 2015; Lawn et al. 2014; Melamed et al. 2007; Raad, Karlawish, and Appelbaum 2009; Rees and Reed 2016; Yates, 2016), and stroke (Hammel et al. 2006); but information on the voting participation characteristics of other neurodegenerative condition subgroups such as epilepsy, Huntington disease, Parkinson's disease, amyotrophic

This is the author's manuscript of the article published in final edited form as: 
lateral sclerosis, and (the focus of the current study) TBI, remains less robust. While the chances of a race being decided by tossing a coin is very small, ${ }^{1}$ federal, state and local elections are often decided by narrow margins (Hayes 2017; Mulligan and Hunter 2003; Teixeira 2001). Additional justification for this particular paper lies in the theory of inclusive democracy (Young 2002) and political equality: who votes matters in terms of who gets elected and which group become represented in the decision-making processes. This, ultimately, makes a difference in terms of whose preferences are accommodated in outputs of legislation. Thus, understanding who votes and who does not is increasingly important, but especially in populations experiencing disenfranchisement - either legally-imposed or self-imposed. Thus, the research question we consider herein is: "how do voters with TBI differ from individuals with TBI who do not vote?"

\section{Voting Among Those with Cognitive Decline}

Scholarship on disenfranchisement among U.S. citizens with neurological and neurodegenerative conditions is both sparse and narrowly focused. Empirical research on voting among the neurological/neurodegenerative subgroup of dementia has focused primarily upon the elderly and progressive dementia disorders such as Alzheimer's disease. Work by Appelbaum (2000) has examined cognitive capacity to vote in this population, and Karlawish et al. (2002) show that those mildly affected by dementia can and did independently cast a vote in the 2000 election. More recent work by Karlawish and his colleagues (2008) shows that long-term care facility staff assessed the capacity to vote of patients across facilities in different ways (independent of government authorization or direction, and without any standardized assessment tool), and used those informal observational assessments in deciding whether to assist residents in registering and voting. Such a non-standardized process could be subject to raising the threshold of competence beyond that of the general population --- resulting in illegal and systematic disenfranchisement, and/or to voter participation suppression secondary to partisan motivation.

While interesting parallels may be drawn between the experiences of individuals with Alzheimer's disease and those with TBI, caution must be taken in generalization of these results to those with TBI. One population is in a state of cognitive decline, while the other is in a constant state of recovery. Despite the differences among these differing populations, we draw two parallels. First, the decisions of caregivers to encourage or resist voting in individuals with TBI may be similar, as those with cognitive impairments may present similar challenges to caregivers in terms of activities of daily living. Second, we apply cognitive assessment tools designed for cognitive impairment across populations to examine levels of understanding of voting. Appelbaum, Bonnie, and Karlawish (2005) use a standardized competency assessment tool specifically designed to test ability to vote among individuals - the "Competency Assessment Tool for Voting" or CAT-V (Appendix), developed out of criteria laid out in a 2001 federal district court decision, Doe v. Rowe. The so-called "Doe Standard" comprises the first three questions in the CAT-V, addressing whether the individual understands the nature and effect of voting, and whether the respondent can make a choice between two candidates (Appelbaum, Bonnie, and Karlawish 2005). The remaining questions are extra-Doe questions which include two questions measuring "reasoning" (can one state why one of the two candidates chosen is "better" and how this decision would affect one's future?) and one question measuring "appreciation" for voting

\footnotetext{
${ }^{1}$ Coin tosses or other random selection methods literally decide tied election contests. A 2017 tied Virginia House of Delegates race was decided by "placing both names in old film canisters and shuffling them in a clear bowl" (see Hayes 2017).
} 
(will the respondent vote in the next election?). The scoring criteria show good inter-rater reliability as measured by the kappa statistic: understanding the nature of voting (0.91), understanding the effect of voting (0.91), being able to make a choice (1.0), comparative reasoning (0.77), consequential reasoning (0.74), and appreciation (0.87). Appelbaum and his colleagues (Appelbaum, Bonnie, and Karlawish 2005) find the scores on the CAT-V demonstrate a strong correlation with the potential voters' cognitive impairment, measured objectively by the widelyused Mini-Mental State Examination (MMSE), a brief 30 question questionnaire used to screen for cognitive impairment overall.

\section{Traumatic Brain Injury: Definition, Incidence, and Prevalence}

Traumatic brain injury is defined as "an alteration in brain function, or other evidence of brain pathology, caused by an external force" (Menon et al 2010, 1637). TBI may result from motor vehicle accidents, falls, explosions, assaults and sports injuries (Langlois, Rutland-Brown, and Thomas 2006). Increasingly, TBI is not just viewed as a single event issue, but rather through the lens of a chronic disease paradigm with long-term impairment in physical, cognitive, behavioral, and social function domains that impact the patient for decades (Dikmen et al 2009; Dikmen, Machamer, and Temkin 2017). Football players (Clark et al. 2017; Coughlin et al. 2017; Farmer 2010; Martin 2012; Merz, van Patten, and Lace 2017; Neale 2009; Storrs 2009) and returning soldiers dominate the popular media when it comes to discussion of TBI. According to a Veterans Health Initiative Independent Study Course sponsored by the Department of Veterans Affairs, 24,559 (37\%) of veterans presenting to the VA Healthcare System from operation Iraqi Freedom (OIF)/Enduring Freedom (OEF), were confirmed to have sustained a TBI (Vanderploeg et al. 2010). A 2017 follow-up study found that $17.3 \%$ of a random sample of 1,388 post-9/11 veterans met criteria for TBI (Lindquist, Love, and Elbogen 2017). There is an estimated 2.8 million Americans who sustain a TBI each year (Faul, Wald, and Coronado 2010; Taylor et al. 2017). It is estimated that 3.2 million Americans are living with some sort of disability related to prior TBI (Corrigan, Selassie, and Orman 2010). In 2016, The Centers for Disease Control and Prevention reported the results of a nearly 10-year study of the incidence rates of combined TBIrelated emergency department visits, hospitalizations, and deaths, finding a slow and steady increase in the united states from $0.8 \%(82.7$ per 100,000$)$ of the U.S. population to $0.9 \%(91.7$ per 100,000), (Centers for Disease Control and Prevention 2016). Lifetime prevalence data suggest that TBI is most prevalent in men, older African-Americans, and younger Whites in poverty (Kisser et al. 2017).

\section{Barriers to Political Participation}

Traditional political behavior theories concerning voting emphasize resources available to vote (time, income, civic skills as in Brady, Verba, and Schlozman 1995). Education and age positively correlate with voting (e.g., Ansolabehere and Hersh 2013; Strate et al. 1989; Verba, Schlozman, and Brady 1995). Research also examines social connections that matter to voting (e.g., Knack 1992), including marriage. For example, scholars have consistently found that "married people are substantially more likely to vote than single people" (Leighley and Nagler 2014, 77; see also Jennings 1979). Legal/institutional structures are also widely studied including voter registration laws (as in Squire, Wolfinger, and Glass 1987), modes of voting (e.g., Leighley and Nagler, 2014) and whether or not government-issued photo identification is required to vote 
(e.g., Alvarez, Bailey, and Katz 2008). Most obviously, however, scholars know that individuals are more likely to participate in a Presidential election than a midterm or local election.

For individuals with TBI, as Belio and colleagues show using the Grid for Measurement of Activity and Participation (G-MAP), within the TBI population, voting is more difficult than other activities such as personal hygiene, looking after one's health, dressing/laundry, housework, managing a family budget, shopping (e.g. groceries and home goods), interpersonal relationships (with family, friends, or acquaintances), and leisure activity (Belio et al. 2014). Research has indicated that there are state laws that could bar those with TBI from voting, explicit in Constitutional language, statute or precedence from court decisions (Hurme and Applebaum 2007). Certainly, some individuals with TBI may be under guardianship, which disqualifies them from voting in about four states (Link et al. 2012) but because physical behaviors may resemble a person who is intoxicated (slurred speech, poor balance, etc.), individuals with TBI may expect or experience more problems at the polls than people without disabilities (Schur and Kruse 2000; Schur and Kruse 2009). Furthermore, those with TBI tend to lose their employment and relocate more often than the general population because of financial hardship (Penna et al. 2010). Political behavior scholars have found that mobility is a key barrier to registering to vote (e.g., Squire, Wolfinger, and Glass 1987) resulting in a lower likelihood of voting for those with lower mobility. Given that many may have impaired working memory and information processing skills (McAllister et al. 2001; McDowell, Whyte, and D'Esposito 1997), "stating one's name and address" which is required identification as of this writing in North Carolina is a challenge. ${ }^{2}$ Some individuals with TBI are unable to drive after their injury (Rapport, Bryer, and Hanks 2008), and as a result photo identification in the form of a driver's license or age of majority card, are not nearly as easy to obtain as may be true for the general population.

\section{Research Aims}

The present research is part of a larger agenda to understand the experience (e.g., thoughts and feelings) associated with a simple form of political participation (voting) from the perspective of individuals living with TBI. This line of research has revealed several insights about adults with TBI and their political participation. Using a qualitative research approach consisting of interviews of individuals with moderate to severe TBI during the Presidential Election 2010, Davis and colleagues (Davis et al. 2010; Hirsch et al 2010) finds that individuals with TBI expressed the view that cognitive capacity to vote should not be a factor in voting but that some people with high levels of cognitive impairment should not vote if they do not understand what is going on. One other study (Link et al. 2012) shows that those with TBI scored similarly to healthy controls on competence to vote and election-specific knowledge.

The aim of the present study is to discover and delineate characteristics of voters or nonvoters with TBI. Understanding the characteristics of those who are franchised versus those who are disenfranchised may give us insights into what sorts of programs could be developed to assist those individuals with TBI, legally entitled to vote, greater access to the exercising of their political voice.

\section{Method}

\footnotetext{
${ }^{2}$ Stating one's name and address is the current identification requirement for voting in North Carolina as of this writing, but states do differ. For current identification requirements across the United States, see http://www.ncsl.org/research/elections-and-campaigns/voter-id.aspx (accessed 27 March 2018).
} 


\section{Participants}

The participant characteristics are listed in Table 1. Potential participants with TBI were identified through the Carolinas Rehabilitation TBI Model Systems registry (Hammond and Malec 2010). Individuals with a diagnosis of TBI who consent to participate in the Model Systems study are entered into the TBI registry at Carolinas Rehabilitation. The registry, which at the time of subject recruitment held 782 names of individuals with TBI, dates back to January $5^{\text {th }}$, 1999 when Carolinas Rehabilitation began enrolling TBI patients into the Model Systems database. Our convenience sample of persons with TBI was drawn from this population of individuals through referrals made by the research and clinical staff at Carolinas Rehabilitation in 2007. To be eligible, the individual with TBI had to be a U.S. citizen, 18 years or older, who had sustained his/her TBI more than six months prior to election day in May 2007.

Data were collected during three different election cycles in Mecklenburg County, North Carolina: a primary held in May, 2007, a general election held for mayor and other such offices in November 2007 and the general election held in November 2008; one-third of our sample was interviewed in each election cycle. All participants gave voluntary informed consent and the study was approved by the Institutional Review Board of Carolinas Medical Center.

\section{Procedure}

\section{Testing Procedure}

The mini-mental state exam (MMSE) and CAT-V (the first three questions of the CAT-V are the Doe voting capacity score) were administered by reading all questions aloud and providing the questions in writing to each participant during seated face-to-face interviews following a standardized protocol (Link et al. 2012). Questions for the voting efficacy test (Appendix) were taken from the survey of National Election Studies (NES), and options " $\mathrm{f}$ " and "g" were created by Douglas Kruse (Link et al. 2012). All measures were administered individually in 2007 and 2008 by a trained researcher (on average, tests were administered 119 days after the election).

\section{Results}

Table 1 presents the participant characteristics. In total, 51 adults with TBI participated in the study. The majority are male. The average age of the sample is 41 years old (the Census Bureau reports that the median age in Mecklenburg County, NC is 34; 37 is the median age in the United States). Of that sample, 64 percent reported having voted in the election cycle.

\section{[INSERT TABLE 1 ABOUT HERE]}

Table 2 provides bivariate correlations of voting (in the election indicated) and the various scores which we hypothesized as surrogates for the "ability" to participate of the respondents. In running the regression, operationalizing the "election" variable as a general election (November 2007 and 2008) versus a primary election (May 2007) yielded similar results. A higher score on the MMSE does not significantly correlate with voting, and three other measures of competence, the court- 
accepted Doe Standard and the two "extra Doe" measures are not significant at conventional levels $(\mathrm{p}<0.05)$.

\section{[INSERT TABLE 2 ABOUT HERE]}

Table 3 indicates that traditional individual-level predictors of voting (education) have no effect on the probability of voting in this group. One of the most important predictors of voting, whether or not the contest is a presidential contest, was not a predictor of the vote among our sample of individuals with TBI. Those with TBI who vote, tend to vote no matter what the type of election is; they are as likely to vote in a contentious presidential election (November 2008) as they are a local mayor's race or a party primary.

Table 3 also shows us that in general terms, those with higher age, CAT-V, MMSE, Doe Scores and Reasoning Scores are more likely to vote than those who have lower scores. The Appreciation Score (will you vote again and why?) is not significantly related to the probability of voting, controlling for other important factors.

The final notable point is that those individuals with TBI who were married, or were not living alone, were significantly less likely to vote; this is notable because it is contrary to what one expects in studies of general population turnout (Jennings 1979; Knack 1992; Leighley and Nagler 2014; Wolfinger and Wolfinger 2008).

\section{[INSERT TABLE 3 ABOUT HERE]}

\section{Discussion}

This is the first known study on voting characteristics in people with TBI who voted and in people with TBI who did not vote. This study demonstrates three key results: 1) there was a significant difference between the Competence Assessment Tool for Voting (CAT-V) total score of participants with TBI who voted and the CAT-V total score of participants with TBI who did not vote and the CAT-V total score predicted voting, 2 ) the age of the participants with TBI was predictive of voting $(\mathrm{p}<0.1)$, and 3$)$ being married was inversely related to voting.

\section{Competence Assessment Tool for Voting (CAT-V)}

The Doe Standard, reasoning or appreciation scores were not predictive of voting, whereas the CAT-V summary score was predictive of voting $(\mathrm{p}<0.05)$. This may be because there was less variation in the overall CAT-V summary score than in the sub-items. Only a few studies have examined CAT-V scores among populations with cognitive conditions. Applebaum and colleagues (Applebaum, Bonnie, and Karlawish 2005) administered the CAT-V to 33 community-dwelling persons with very mild to severe Alzheimer's disease (AD). They found a strong correlation between dementia severity and the capacity to vote. Irastorza and colleagues (Irastorza, Corujo, and Banuelos 2011) administered the CAT-V to 68 adults with dementia (Alzheimer's disease, $\mathrm{AD})$ and 25 healthy elderly controls living in a senior residence. They found significant differences on all CAT-V items between the two groups. Tiraboschi and colleagues (2011) administered the CAT-V to 38 subjects with mild to moderate AD in a day-patient facility in Bergamo, Italy 30 to 60 days before the 2006 Italian general elections. Only a small minority of AD subjects (3/38), at mild disease severity, achieved the maximum score on the CAT-V. Raad 
and colleagues (Raad, Karlawish, and Applebaum 2009) administered the CAT-V to a sample of 52 community-dwelling adults with serious mental illness. Most $(>80 \%)$ of the participants achieved high scores on the CAT-V summary score.

\section{Age}

Most studies of the relationship between age and voter turnout in the general population suggest that voting activity increases "from young adulthood through middle age and then decrease for those past middle age," (Curtis and Lambert 1976) in a non-linear fashion (Ansolabehere, Hersh, and Shepsle 2012; Ansolabehere and Hersch 2013). Although there is a paucity of literature examining the effect of age upon voter turnout among individuals with neurologic impairment, research shows that in the spinal cord injured (SCI) population voting rates increase with chronological age --- just not as with nearly as robust of an effect as in the general population (Schur and Kruse 2000). We find that the age of the subject with TBI is predictive of voting (see Table 3). However, in the general population, research indicates that age-related changes in community attachment, strength of partisanship, church attendance, government responsiveness, family income, employment status, and civic competence are all known to account for about $50 \%$ of age-related increases in voting (Strate et al. 1989). Each of these factors are variables that may deviate from the natural history of family development status-post injury --- influencing voter participation as a result. Differences in community support, and/or introduction of the aforementioned impact factors at different points in the life span of the participants with TBI relative to the general population may result in some subtle differences (e.g. non-linear versus possibility of linear relationship) in the impact of age upon voting participation between groups and may be an interesting area for future research.

There is a growing amount of research that does consider age as a control; these incidental findings show the effect of chronological age upon capacity to vote and voter turnout among individuals with mental illness and neurodegenerative conditions. Yet the mixed findings highlight the need for more work specifically about those with TBI. In a 2009 study examining the capacity to vote of persons with serious mental illness Raad, Karlawish, and Appelbaum (2009) found no statistical impact of age of 52 subjects 23 to 69 years-of-age, upon capacity to vote. A 2005 study of 33 subjects that examined the capacity to vote among a slightly older group of communitydwelling subjects (59 to 97 years-of-age) living with Alzheimer's disease similarly found no impact of age upon capacity to vote (Applebaum, Bonnie, and Karlawish 2005). A 2011 Spanish study examined capacity to vote in persons with dementia, finding that capacity to vote decreases as a function of age. Closer examination reveals that similar to the aforementioned studies, no correlation existed between capacity to vote and age among 61 year-old to 89 year-old subjects. It was only when a 90 to 99 year-old group (not examined in earlier studies) was included, that a non-linear inverse relationship emerged between age and capacity to vote (Irastorza, Corujo, and Banuelos 2011). It is unclear, therefore, if this finding is more a function of age (e.g. would be seen in all neurologically impaired sub-populations that included subjects 90 years-of-age and older in their datasets) or is unique to the voters with neurodegenerative conditions.

\section{Marital Status}

In sharp contrast to the general population, where marriage increases the likelihood that an individual will vote (Leighley and Nagler 2014; Wolfinger and Wolfinger 2008) married 
individuals with TBI were less likely to participate in the voting process. Stoker and Jennings (1995) offer a potential reason - marital transitions tend to depress turnout, especially transitions in marriages among younger individuals. While the transitions Stoker and Jennings consider are new marriages, new divorces and deaths - these are situations where individuals must "undergo a period of substantial adjustment in their personal lives, both in emotional terms and in terms of their day-to-day life-style" (430). Consider the potential effects of an unexpected TBI; it might be considered a constant transition from the planned family dynamics pre-injury.

Yet prior research suggests that patients perceived to have successfully graduated from inpatient hospital rehabilitation are encouraged by their families to engage in patient advocacy (Schur 1998). The results of this study raise the possibility that families of individuals with moderate to severe TBI do not view their family member as having been truly successful in rehabilitation --- or that the definition of a successful clinical outcome is incongruent with the family's views of a successful outcome. An alternative possibility is that families of individuals with moderate to severe TBI encourage their loved ones to engage in advocacy and political engagement --- activities up to the point of actually voting. A recent catch phrase among the disability community has been "Nothing about me without me." We think understanding the nature of the barriers faced by a diversity of individuals with TBI, both conscious/intentional and unconscious/unintentional can help us understand how to develop programs to help those who wish to vote, to vote in the future. With that participation, it makes the electorate more representative of everyone, but also makes it more likely that this group will be represented when policy is made. More research is needed to clarify the association between TBI, voting and marriage.

\section{Limitations}

Our study is not without limitations. We used a relatively small convenience sample of ambulatory, literate, community-dwelling individuals with moderate to severe TBI, majority male, who were not randomly drawn from the population, therefore, may not be fully representative of the entire population of individuals with TBI. Additional research should examine CAT-V among individuals with lesser degrees of education and literacy, and with greater enrollment of females and injury severity of mild, moderate and severe grades, residents in nursing homes, and people with mobility impairments. This could assist in identifying groups at higher risk for not voting and thus permit more targeted assessments of such persons (Applebaum, Bonnie, and Karlawish 2005). The sample represents individuals who voted in a single city in the Southern United States. Characteristics of voters vary by U.S. geographic region and by country. In addition, although our study finds that age is a significant predictor of voting, we did not, however, account for what Ansolabehere and colleagues $(2012,334)$ call the Stayer-Mover model of registration: "Even with a constant rate of registering across the life-span, the model highlights that the longer a person lives and does not move, the greater is the probability that the person is in the [registration] system" (334). Once someone is registered, they are more likely to vote. Put another way, we do not account for residential stability when considering that age increases the probability of voting.

A shift in state policies has expanded a singular Election Day to a multi-week voting period. Partisans and older voters disproportionately take advantage of early voting, and younger individuals (i.e. newly wounded veterans) who take advantage of early voting tend to do so later in the early-voting period (Vivekinan et al. 2016). It is not known how CAT-V scores affect behavior when it comes to early voting, nor does our data shed light on what sort of effect early 
voting or convenience methods affect the negative relationship we find concerning marriage. We believe these are important topics for future research. Nevertheless, this study represents the largest study to date on voting empowerment in this population.

\section{Conclusion and Policy Implications}

We find that there is variation in voting even among this small sample interviewed for the present study, and that the variation is predictable. Those with the highest CAT-Vs are the most likely to vote. In addition, we find that traditional predictors of voting simply aren't predictors among this TBI group, and even one, whether the person is married, has a negative effect on voting.

One of the central questions in democratic government is who should have the right to vote? Although scholars have argued it is unconstitutional to prevent people with mental, incapacity from voting, states still exclude from voting people with mental impairments (Schriner and Batavia, 2002; Schriner, Ochs, and Schields 1997; Schriner, Ochs, and Schields 2000; Schur, Schields, and Schriner 2003). Schriner and Ochs (2000) state that prohibiting participation can have negative effects at the societal level...By ignoring the constitutional guarantees to equal treatment under the law, the fabric of the political society is weakened. By refusing to face the mythology of incapacity that surrounds the disability distinction in electoral qualifications, we lose the opportunity to take another step toward ensuring [equal] representation in democratic governance. In hindsight, we may one day decide that in limiting the citizenship rights of people with cognitive and emotional impairments, we have disabled democracy itself (Schriner and Ochs 2000, 183).

Yet, all too often, those with mental incapacity of various types have been a group denied suffrage (Hurme and Appelbaum 2007). In terms of public policy, consistent with other scholarship, we argue that the implication of this work is that suffrage restrictions are likely "overexclusive" (e.g., Beckman 2014; Hurme and Appelbaum 2007). We argue that at a minimum, these results suggest that lawmakers should not make blanket policies concerning the voting rights of those with mental incapacities. For example, until recently, California had such a blanket law. However, according to the Secretary of State's website, "California recently amended its laws regarding the limitation of a person's right to vote based on his or her mental incompetence and conservatorship status. Specifically, Senate Bill (SB) 589 (Block, Chapter 736 of the Statutes of 2015) amended several sections of the Elections Code and the Probate Code related to the voting rights of persons subject to a conservatorship (conservatees)." ${ }^{3}$ We argue that other states should follow the lead of California, particularly since there is such a wide variation among individuals with TBI, especially in terms of their cognitive capacity. Clearly, there are individuals who want to vote.

Another central question in democratic government is whether participation in voting affects the health of the public. Research suggests an interrelationship between voting and health issues. Two studies on voting and health conducted in the U.K. and the U.S. by Denny and Doyle (2007) and Blakely, Kennedy, and Kawachi (2001) found that citizens experiencing poor mental or physical health were more likely to abstain from voting than citizens reporting excellent or good health. Arah (2008) used data from the National Child Development Study of a cohort born in a single week in Britain in March of 1958 and found that abstaining from voting in the election of 1979 increased the odds of reporting poor health in 1981, 1991, 2000 and 2004, after controlling

\footnotetext{
${ }^{3}$ California Secretary of State. 2018. "Voting Rights: Persons Subject to Conservatorship." http://www.sos.ca.gov/elections/voting-info/conservatorship/ (accessed 15 June 2018).
} 
for socioeconomic factors (including age, gender, location, chronic illness, smoking and alcohol use). These studies suggest poor political participation harms health, and poor health, in turn, hampers political participation. Future research ought to investigate whether political participation (specifically voting, but also other forms of political participation including participation in demonstrations/peaceful protests) improves cognitive health of those with cognitive impairment. Until further research is conducted, the association between voting and changes in health status of those living with TBI remains speculative.

Although we did not assess specific mental health issues, health literacy, loss of work, financial hardship (Sabella, Andrzejewski, and Wallgren 2018), or incarceration (Schofield et al. 2006) in relation to voting, some of these events, such as poor mental health and incarceration, may affect voting among people with TBI. Internationally, $25 \%$ to $87 \%$ of incarcerated male and female prisoners report a history of mild to severe TBI and TBI associated mental health problems and impaired cognitive performance (Ferguson et al. 2012; Pitman et al. 2015; Schofield et al. 2006; Slaughter, Fann, and Ehde 2003), compared to $8.5 \%$ in a general population with a history of TBI and associated mental health problems (Silver et al. 2001). It is plausible that TBI related problems after release from jails or prisons and lingering mental health and cognitive issues could trigger disenfranchisement among people with TBI leading them to be less likely to be registered to vote, and less likely to vote during elections than individuals with other disabilities (Ott, Heindel, and Papandonatos 2003; Keeley et al. 2008).

How could accessibility and participation (including issues of independence and privacy) during the electoral process be assured for individuals with impairments that affect communication, perception, attention, memory, reasoning, the ability to read, interpret written language, understand directions, navigate the (computerized) ballot or polling place, or chose between two or more candidates or political platforms - behaviors that citizens with TBI might reasonably have difficulty with. Such a person might require rehabilitation supports in the community and modifications of polling place practices to allow an individual of the voters' choice to assist the voter in casting the ballot by reading the ballot and providing unbiased explanation of ballot measures or allowing an election worker to provide assistance in use of new computerized technologies (Schur, Adya, and Ameri 2015). Election officials receive manualized training on assisting citizens with disabilities at the polls. We are not aware of any data on the effect of election official training on participation of voters with TBI/cognitive limitations. Greater provision of basic training to increase knowledge about mental incapacity or TBI among election officials could potentially facilitate participation of voters with cognitive limitations.

Finally, there is a paucity of research on voting of persons who need assistance at the polls, many of whom have TBI, but some who are simply old, or cognitively impaired, and how to solicit whether someone needs assistance and how to provide that assistance. Similarly, research on political participation or voting among people with neurologic conditions has yet to examine why disenfranchisement might be self-imposed. Perhaps self-imposed disenfranchisement is due to factors including low self-efficacy or lack of motivation, or simply because people with disabilities are less likely to go and vote if they expect problems at the polls (Schur and Kruse 2009; Schur and Kruse 2010), or perhaps self-imposed disenfranchisement is the brains way of conserving energy for daily activities that matter for survival (work, sleep, eating) at the expense of voting (Verba, Schlozman, and Brady 1995). Future research is needed to study/analyze those with TBI to understand why people with TBI do not vote and why voting matters. Research could lead to new insights into obstacles to voting participation faced by citizens with mental incapacity or TBI so that these citizens are able to vote in a manner that provides the same opportunity for access 
and participation as for other voters and provides specific recommendations to the United States Election Assistance Commission to facilitate participation of voters with cognitive limitations (Lampel 2011).

Mark A. Hirsch, PhD, Senior Scientist, Department of Physical Medicine and Rehabilitation, Carolinas Rehabilitation, Carolinas Medical Center, Atrium Health.

Martha E. Kropf, PhD, Professor of Political Science \& Public Administration and Core Faculty of the Public Policy Program at the University of North Carolina at Charlotte.

Flora M. Hammond, MD, Professor and Chair of Physical Medicine and Rehabilitation at Indiana University School of Medicine; Chief of Medical Affairs and Brain Injury Medical Director at the Rehabilitation Hospital of Indiana; and Executive Chair of the Traumatic Brain Injury Model System.

Lisa Schur, JD, PhD, Professor and Chair, Department of Labor Studies and Employment Relations, Rutgers University.

Jason H. Karlawish, MD, Professor of Medicine, Medical Ethics and Health Policy, and Neurology; Perelman School of Medicine, University of Pennsylvania.

Andrew M. Ball, PT, DPT, PhD, OCS, board certified orthopaedic physical therapist treating patients at Atrium Health, Vice President of Quality and Performance at NxtGen Institute, and a dry needling instructor for Myopain Seminars.

\section{Notes}

Conflicts of interest: None declared.

Corresponding author: Mark Hirsch, Mark.Hirsch@atriumhealth.org

We thank the persons with TBI for so generously giving their time as well as Dr. Christine Davis and Dr. Douglas Kruse for scholarly support, Susan Saunders, Dr. Allison K. Bickett, Kimberly Lang, Tamie Guerrier, Veronica Ridpath and the reviewers for helpful comments on previous versions of this manuscript.

This study was partially supported by National Institutes of Health grant HD055202-01, HD055202-02S1 and by a grant from Carolinas HealthCare Foundation, Charlotte, North Carolina. 


\section{References}

Agran, Martin, William E. MacLean Jr., Katherine Anne Kitchen. 2016. "My Voice Counts Too: Voting Participation Among Individuals with Intellectual Disability." Intellectual and Developmental Disabilities 54(4): 285-294.

Alvarez, Michael R., Delia Bailey, and Jonathan N. Katz. 2008. "The Effect of Voter Identification Laws on Turnout." California Institute of Technology Social Science Working Paper No. 1267R. http://dx.doi.org/10.2139/ssrn.1084598 (Accessed 23 January 2019).

Ansolabehere, Stephen, and Eitan Hersh. 2013. "Gender, Race, Age and Voting: A Research Note." Politics and Governance 1(2): 132-137.

Ansolabehere, Stephen, Eitan Hersh and Kenneth Shepsle. 2012. "Movers, Stayers, and Registration: Why Age is Correlated with Registration in the U.S." Quarterly Journal of Political Science 7(4): 333-363.

Appelbaum, Paul S. 2000. 'I Vote, I Count': Mental Disability and the Right to Vote.' Law and Psychiatry 51(7): 849-885

Appelbaum, Paul S., Richard J. Bonnie, and Jason H. Karlawish. 2005. "The Capacity to Vote of Persons With Alzheimer's Disease.’'American Journal of Psychiatry 162(11): 2094-2100.

Arah, Onyebuchi A. 2008. "Effect Of Voting Abstention and Life Course Socioeconomic Position On Self-Reported Health." Journal of Epidemiology and Community Health 62(8): 759760 .

Beckman, Ludwig. 2014. "The Accuracy of Electoral Regulations: The Case of the Right to Vote by People with Cognitive Impairments.” Social Policy \& Society 13(2): 221-233.

Belio, Christian, Antoinette Prouteau, Michele Koleck et al. 2014. "Participation Restrictions in Patients with Psychiatric and/or Cognitive Disabilities: Preliminary Results for an ICFDerived Assessment Tool." Annals of Physical and Rehabilitation Medicine 57: 114-137.

Blakely, Tony A., Bruce P. Kennedy, and Ichiro Kawachi. 2001. "Socioeconomic Inequality In Voting Participation And Self-Rated Health.” American Journal of Public Health 91(1): 99-104.

Brady, Henry E., Sidney Verba and Kay Lehman Schlozman. 1995. "Beyond SES: A Resource Model of Political Participation.” American Political Science Review 89(2): 271-294.

Clark, Michael D., Brenton M. Asken, Stephen W. Marshall and Kevin Guskiewicz. 2017. "Descriptive Characteristics of Concussions in National Football League Games, 20102011 to 2013-2014." American Journal of Sports Medicine 45(4): 929-936. 
Centers for Disease Control and Prevention. 2016. "Rates of TBI-Related Emergency Department Visits, Hospitalizations, and Deaths - United States, 2001-2010." https://www.cdc.gov/traumaticbraininjury/data/rates.html. (Accessed 20 June 2018).

Corrigan, John D., Anbesaw W. Selassie and Jean A. (Langlois) Orman. 2010. "The Epidemiology of Traumatic Brain Injury.” Journal of Head Trauma Rehabilitation 25(2): $72-80$

Coughlin, Jennifer M., Yuchuan Wang, Il Minn et al. 2017. "Imaging of Glial Cell Activation and White Matter Integrity in Brains of Active and Recently Retried National Football League Players." Journal of the American Medical Association Neurology 71(1): 67-74.

Curtis, James E., and Ronald Lambert. 1976. "Voting, Election Interest, and Age: National Findings for English and French Canadians." Canadian Journal of Political Science 9(2): 293-307.

Davis, Christine, Julia Nelson, Mark A. Hirsch et al. 2010. “An Exploratory Examination of Political Empowerment and Voting Among Individuals with TBI." Brain Injury 24(3): 208.

De Cauwer, Harald. 2005. “Are Cognitively Impaired Older Adults Able to Vote?” Geriatrics 60(3): 13-14.

Denny, Kevin J., and Orla M. Doyle. 2007. "Take Up Thy Bed, And Vote" Measuring The Relationship Between Voting Behaviour And Indicators Of Health." European Journal of Public Health 17(4): 400-401.

Dikmen, Sureyya, John D. Corrigan, Harvey S. Levin, Joan Machamer, William Stiers, and Marc G. Weisskopf. 2009. "Cognitive Outcome Following Traumatic Brain Injury." Journal of Head Trauma Rehabilitation 24(6): 430-438.

Dikmen Sureyya, Joan Machamer, and Nancy Temkin. 2017. "Mild Traumatic Brain Injury: Longitudinal Study of Cognition, Functional Status, and Post-Traumatic Symptoms." Journal of Neurotrauma 34(8): 1524-1530.

Doron, Adiel, Rena Kurs, Tali Stolovy, Aya Secker-Einbinder, and Alla Raba. 2014. "Voting Rights for Psychiatric Patients: Compromise of the Integrity of Elections or Empowerment and Integration into the Community?" The Israel Journal of Psychiatry and Related Sciences 51(3): 169-231.

Farmer, Sam. 2010. "NFL is taking the long-term impact of concussions seriously." Los Angeles Times. $\quad$ http://articles.latimes.com/2010/sep/11/sports/la-sp-nfl-concussions-20100912. (Accessed 20 June 2018).

Faul, Mark, Likang Xu, Marlena M. Wald, and Victor G. Coronado. 2010. "Traumatic Brain Injury in the United States: Emergency Department Visits, Hospitalizations, and Deaths." Atlanta 
(GA): Centers for Disease Control and Prevention, National Center for Injury Prevention and Control. https://www.cdc.gov/traumaticbraininjury/pdf/blue book.pdf (Accessed 22 January 2019).

Ferguson, Pamela, Emily Pickelsimer, John Corrigan, Jennifer Bogner, and Marlena Wald. 2012. "Prevalence of Traumatic Brain Injury Among Prisoners in South Carolina." Journal of Head Trauma Rehabilitation 27(3): E11-E20.

Hammel, Joy, Robin Jones, Andrea Gossett, and Elizabeth Morgan. 2006. "Examining Barriers and Supports to Community Living and Participation after a Stroke from a Participatory Action Research Approach." Topics in Stroke Rehabilitation: Occupational Therapy Innovations 13(3): 43-58.

Hammond, Flora, and James Malec. 2010. "The Traumatic Brain Injury Model Systems: A Longitudinal Database, Research, Collaboration and Knowledge Translation." European Journal of Physical and Rehabilitation Medicine 46(4): 545-548.

Hayes, Christal. 2017. "Virginia Election Tie: Coin Tosses, Picking Names in a Hat? Yep, That's How Some Races Are Decided." TSA Today https://www.usatoday.com/story/news/2017/12/21/virginia-election-tie-coin-tossespicking-names-hat-yep-thats-how-races-decided-probably-never-going/973630001/ (Accessed 20 June 2018).

Hirsch, Mark A., Andrew M. Ball, Christine S. Davis, and Flora M. Hammond. 2010. "The Experience of Voting Among Individuals with Traumatic Brain Injury and Family Members.' Paper presented at the 2010 Midwest Political Science Association Meeting, Chicago, IL, April 22.

Hurme, Sally Balch and Paul S. Appelbaum. 2007. "Defining and Assessing Capacity to Vote: The Effect of Mental Impairment on the Rights of Voters.' McGeorge Law Review 38: 931-979.

Irastorza, Luis Javier, Pablo Corujo, and Pilar Banuelos. 2011. "Capacity to Vote in Persons with Dementia and the Elderly." International Journal of Alzheimer's Disease Article ID 941041. doi:10.4061/2011/941041

Jennings, M. Kent. 1979. “Another Look at the Life Cycle and Political Participation.” American Journal of Political Science 23: 755-771.

Karlawish, Jason H. 2008. "Voting by Older Adults with Cognitive Impairments." Leonard Davis Institute Issue Brief 13(4): 1-4.

Karlawish, Jason H., David Casarett, Bryan James, Kathleen Joy Propert, and David A. Asch. 2002. "Do Persons with Dementia Vote." Neurology 58(7): 1100-1102. 
Karlawish, Jason H., Richard J. Bonnie, Paul S. Appelbaum et al. 2008. "Identifying the Barriers and Challenges to Voting by Residents in Nursing Homes and Assisted Living Settings." Journal of Aging and Social Policy 20(1): 65-79.

Kisser, Jason, Shari R. Waldstein, Michelle K. Evans, and Alan B. Zonderman. 2017. "Lifetime Prevalence of Traumatic Brain Injury in a Demographically Diverse Community Sample." Brain Injury 31(5): 620-623.

Knack, Stephen. 1992. "Civic Norms, Social Sanctions and Voter Turnout." Rationality and Society 4: 133-156.

Langlois, Jean A., Wesley Rutland-Brown, and Karen E. Thomas. 2006. "Traumatic Brain Injury in the United States: Emergency Department Visits, Hospitalizations, and Deaths.” Atlanta, GA: Centers for Disease Control and Prevention, National Center for Injury Prevention and Control. https://stacks.cdc.gov/view/cdc/12294 (Accessed January 22 2019).

Lampel, Katherine. 2011. "DoD To Test Voting Technology For Wounded Warriors”. Federal Voting Assistance Program.

Lawn, Sharon, John McMillan, Zinaida Comley, Ann Smith, and John Brayley. 2014. "Mental Health Recovery and Voting: Why Being Treated as a Citizen Matters and How We Can Do It." Journal of Psychiatric and Mental Health Nursing 21(4): 289-295.

Leighley, Jan E., and Jonathan Nagler. 2014. "Who Votes Now? Demographics, Issues, Inequality, and Turnout in the United States.” Princeton: Princeton University Press.

Lindquist, Lisa K., Holly C. Love, and Eric B. Elbogen. 2017. "Traumatic Brain Injury in Iraq and Afghanistan Veterans: New Results From a National Random Sample Study." The Journal of Neuropsychiatry and Clinical Neurosciences 29(3): 254-259.

Link, Jessica N., Martha Kropf, Mark A. Hirsch et al. 2012 "Assessing Voting Competence and Political Knowledge: Comparing Individuals with Traumatic Brain Injuries and "Average" College Students.” Election Law Journal 11(1): 52-69.

Martin, Michel. 2012. "Can the NFL Keep Fans Excited and Players Safe?" National Public Radio. $\quad$ http://www.npr.org/2012/08/07/158361382/can-the-nfl-keep-fans-excited-andplayers-safe (Accessed 20 June 2018).

McAllister, Thomas W., Molly B. Sparling, Laura A. Flashman, Stephen J. Guerin, Alexander C. Mamourian, and Andrew J. Saykin. 2001. "Differential Working Memory Load Effects after Mild Traumatic Brain Injury.” Neuroimage 14(5): 1004-1012.

McDowell, Sharon, John Whyte, and Mark D’Esposito. 1997. "Working Memory Impairments in Traumatic Brain Injury: Evidence from a Dual-Task Paradigm.” Neuropsychologia 35(10): 1341-1353. 
Melamed, Yuval, Adiel Doron, Boris Finkel et al. 2007. "Israeli Psychiatric Inpatients Go To The Polls." Journal of Nervous and Mental Disorders 195: 705-708.

Menon, David K., Karen Schwab, David W. Wright, and Andrew I. Maas. 2010. "Position Statement: Definition of Traumatic Brain Injury." Archives of Physical Medicine and Rehabilitation 91(11): 1637-1640

Mertz, Zachary, Ryan Van Patten, and John Lace. 2017. "Current Public Knowledge Pertaining to Traumatic Brain Injury: Influence of Demographic Factors, Social Trends, and Sport Concussion Experience on the Understanding of Traumatic Brain Injury Sequelae." Archives of Clinical Neuropsychology 32(2): 155-167.

Mulligan, Casey B,. and Charles G. Hunter. 2003. "The Empirical Frequency of a Pivotal Vote." Public Choice 116(1-2): 31-54.

Neale, Todd. 2009. "NFL Institutes New Concussion Policy." ABC News. http://abcnews.go.com/Health/MindMoodNews/nfl-institutes-concussionpolicy/story?id=9251126 (Accessed 20 June 2018).

Ott, Brian R., William C. Heindel, and George D. Papandonatos. 2003. "A Survey of Voter Participation by Cognitively Impaired Elderly Patients." Neurology 60: 1546-1548.

Penna, Suzanne, Thomas A. Novack, Nichole Carlson, Miranda Grote, John D. Corrigan, and Tessa Hart. 2010. "Residence Following Traumatic Brain Injury: A Longitudinal Study." Journal of Head Trauma Rehabilitation 25(1): 52-60.

Pitman, Ivan, Claire Haddlesey, Sara Ramos, Michael Oddy, and Deborah Fortescue. 2015. "The Association Between Neuropsychological Performance And Self-Reported Traumatic Brain Injury In A Sample Of Adult Male Prisoners In The UK. Neuropsychological Rehabilitation 25(5): 763-779.

Raad, Raymond, Jason Karlawish, and Paul S. Appelbaum. 2009. "The Capacity To Vote Of Persons With Serious Mental Illness." Psychiatric Services 60(5): 624-628.

Rapport, Lisa J., Renee Coleinan Bryer, and Robin A. Hanks. 2008. "Driving And Community Integration After Traumatic Brain Injury." Archives of Physical Medicine and Rehabilitation 89(5): 922-930.

Rees, Gareth, and James Reed. 2016. "Patients or Prisoners? Time To Voting Rights Of Mentally Disordered Offenders." BJPsych Bulletin 40: 169-172.

Sabella Scott A., Joshua H. Andrzejewski, and Alexandria Wallgren. 2018. "Financial Hardship After Traumatic Brain Injury: A Brief Scale For Family Caregivers". Brain Injury 32(7): 926-932.

Schofield, Peter, Tony Butler, Stephanie Hollis, Nadine Smith, Stephen Lee, and Wendy Kelso. 2006. "Traumatic Brain Injury Among Australian Prisoners: Rates, Recurrence And Sequelae." Brain Injury 20: 499-506. 
Schriner, Kay, and Andrew Batavia. 2002. "The Americans With Disabilities Act: Does It Secure The Fundamental Right To Vote?” Policy Studies Journal 29(4): 663-673.

Schriner, Kay, and Lisa Ochs. 2000. "Making Exceptions to Universal Suffrage: Disability and the Right to Vote.” In C.E. Faupel and P.M. Roman (Eds.), Encyclopedia of criminology and deviant behavior, 179-183: London: Taylor and Francis.

Schriner, Kay, Lisa Ochs, and Todd Shields. 2000. "Democratic Dilemmas: Notes On The ADA And Voting Rights Of People With Cognitive And Emotional Impairments". Berkeley Journal of Employment and Labor Law 21: 437-472.

Schriner, Kay, Lisa A. Ochs, and Todd G. Shields. 1997. "The Last Suffrage Movement: Voting Rights For Persons With Cognitive And Emotional Disabilities.” Publius 27(3): 75-96.

Schur, Lisa. 1998. "Disability and the Psychology of Political Participation." Journal of Disability Policy Studies 9(2): 3-31.

Schur, Lisa, and Meera Adya. 2012. "Sidelined or Mainstreamed? Political Participation And Attitudes Of People With Disabilities In The United States." Social Science Quarterly 94(3): 811-839.

Schur, Lisa, Meera Adya, and Mason Ameri. 2015. "Accessible Democracy: Reducing Voting Obstacles For People With Disabilities.” Election Law Journal: Rules, Politics, and Policy 14(1): 60-65.

Schur, Lisa, Meera Adya, and Douglas Kruse. 2013. "Disability, Voter Turnout, And Voting Difficulties In The 2012 Elections." https://smlr.rutgers.edu/sites/default/files/images/Disability $\% 20$ and $\% 20$ voting $\% 20$ survey \%20report $\% 20$ for $\% 202012 \% 20$ elections.pdf (Accessed 20 June 2018).

Schur, Lisa, and Douglas L. Kruse. 2000. "What Determines Voter Turnout?: Lessons From Citizens With Disabilities.” Social Science Quarterly (81)2: 571-587.

Schur, Lisa, and Douglas Kruse. 2009. "Fact sheet: Disability and Voter Turnout in the 2008 Elections." https://smlr.rutgers.edu/content/disability-and-voter-turnout (Accessed January 30, 2018).

Schur, Lisa, Todd Shields, and Kay Schriner. 2003. "Can I Make A Difference? Efficacy, Employment, And Disability.” Political Psychology 24(1): 119-149.

Silver, Jonathan, Rachel Kramer, Steven Greenwald, and Myrna Weissman. 2001. "The Association Between Head Injuries And Psychiatric Disorders: Findings From The New Haven NIMH Epidemiologic Catchment Area Study.” Brain Injury 15(11): 935-945. 
Slaughter, Bill, Jesse Fann, and Dawn Ehde. 2003. "Traumatic Brain Injury In A County Jail Population: Prevalence, Neuropsychological Functioning And Psychiatric Disorders." Brain Injury 17: 731-41.

Squire, Peverill, Raymond E. Wolfinger, and David P. Glass. 1987. "Residential Mobility and Voter Turnout." American Political Science Review 81(1): 45-65.

Stoker, Laura, and M. Kent Jennings. 1995. "Life-Cycle Transitions And Political Participation: The Case Of Marriage.” American Political Science Review 89(2): 421-433.

Storrs, Carina. 2009. "NFL Gains Yards In Its Treatment Of Players' Head Injuries." Scientific American. https://blogs.scientificamerican.com/observations/nfl-gains-yards-in-itstreatment-of-players-head-injuries (Accessed 20 June 2018).

Strate John M., Charles J. Parrish, Charles D. Elder, and Coit Ford. 1989. "Life Span Civic Development And Voting Participation.” American Political Science Association 83(2): 443-464.

Sund, Reijo, Hannu Lahtinen, Hanna Wass, Mikko Mattila, and Pekka Martikainen. 2017. "How Voter Turnout Varies Between Different Chronic Conditions? A Population-Based Register Study.” Journal of Epidemiology and Community Health 71: 475-479,

Teixiera, Ruy. 2001. "The 2000 Election And The Future Of U.S. Politics." International Journal of Health Services 31(4): 881-887.

Taylor, Christopher A., Jeneita M. Bell, Matthew J. Breiding, and Likang Xu. 2017. "Traumatic Brain Injury-Related Emergency Department Visits, Hospitalizations, and Deaths United States, 2007 and 2013." Morbidity and Mortality Weekly Report: Surveillance Summaries 66(SS-9): 1-16.

Tiraboschi, Pietro, Erica Chito, Leonardo Sacco, Marta Sala, Stefano Stefanini, and Carlo Alberto Defanti. 2011. "Evaluating Voting Competence In Persons With Alzheimer Disease." International Journal of Alzheimer's Disease Article ID 983895. doi:10.4061/2011/983895.

Vanderploeg, Rodney D., Micaela Corins-Pop, Sharon Benedict et al. 2010. "Traumatic Brain Injury." Department of Veterans Affairs Employee Education System.

http://www.publichealth.va.gov/docs/vhi/traumatic-brain-injury-vhi.pdf. (Accessed 20 June 2018).

Verba, Sidney, Kay Lehman Schlozman, and Henry Brady. 1995. "Voice and Equality: Civic Voluntarism In American Politics". Harvard University Press.

Vivekinan, Ashok, Daniel Feder, Mary McGrath, and Eitan Hersh. 2016. "The Dynamic Election: Patterns Of Early Voting Across Time, State Party and Age." Election Law Journal: Rules Politics, and Policy 15(2): 115-128. 
Wolfinger, Nicholas H., and Raymond E. Wolfinger. 2008. "Family Structure And Voter Turnout." Social Forces 86: 1513-1528.

Yates, Tiffany. 2016. "A First Amendment Analysis Of Voting Rights Of The Mentally Incapacitated: Why Are You Calling Me An Idiot, Why Can't I Vote?" First Amendment Law Review 15(1):Article 5. http://scholarship.law.unc.edu/falr/vol15/iss1/5?utm_source=scholarship.law.unc.edu\%2 Ffalr\%2Fvol15\%2Fiss 1\%2F5\&utm_medium=PDF\&utm_campaign=PDFCoverPages (Accessed 22 January 2019).

Young, Iris Marion. 2002. "Inclusion and Democracy". Oxford Scholarship Online, Oxford University Press. 


\section{TABLES AND FIGURES}

\section{Table 1: Participant Characteristics}

\begin{tabular}{|l|l|}
\hline Variable & Description \\
\hline $\begin{array}{l}\text { Voted (in Election Under Consideration at time of } \\
\text { study enrollment) }\end{array}$ & $62.5 \%$ \\
\hline Male & $73.21 \%$ \\
\hline Age (SD) & 40.85 years (16.70) \\
\hline Percent white & $64.29 \%$ \\
\hline Percent married (or living with an adult) & $32.14 \%$ \\
\hline Percent with high school diploma & $85.71 \%$ \\
\hline Interviewed During November 2007 Election & $33.93 \%$ \\
\hline Interviewed During May 2008 Election & $33.93 \%$ \\
\hline Interviewed During November 2008 Election & $32.14 \%$ \\
\hline
\end{tabular}


Table 2: Bivariate Comparisons of Comprehension and Voting

\begin{tabular}{|l|l|l|l|}
\hline Variable Name & $\begin{array}{l}\text { Voters } \\
\text { with TBI } \\
\mathbf{N = 3 1}\end{array}$ & $\begin{array}{l}\text { Non-Voters } \\
\text { with TBI } \\
\mathbf{N = 2 0}\end{array}$ & Difference \\
\hline $\begin{array}{l}\text { CAT-V Score (out of 12 points } \\
\text { total), mean (SD) }\end{array}$ & $10.97(0.35)$ & $9.80(0.59)$ & $1.17(0.64)^{* *}$ \\
\hline $\begin{array}{l}\text { Doe Standard Score (out of six } \\
\text { points total), mean (SD) }\end{array}$ & $5.70(0.15)$ & $5.24(0.27)$ & $0.46(0.28)^{*}$ \\
\hline $\begin{array}{l}\text { Reasoning (Extra Doe) (out of 4 } \\
\text { points), mean (SD) }\end{array}$ & $3.48(0.17)$ & $3.05(0.32)$ & $0.43(0.33)^{*}$ \\
\hline $\begin{array}{l}\text { Appreciation (Extra Doe) (out of 2 } \\
\text { points), mean (SD) }\end{array}$ & $1.73(0.11)$ & $1.47(0.16)$ & $0.26(0.19)^{*}$ \\
\hline MMSE Score, mean (SD) & $26.23(0.59)$ & $25.05(1.12)$ & $1.18(1.15)$ n.s. \\
\hline
\end{tabular}

${ }^{* * *} \mathrm{p}<0.01 ;{ }^{* *} \mathrm{p}<0.05 ;{ }^{*} \mathrm{p}<0.10$; n.s. not statistically significant for a one-tailed test; MMSE, Mini-Mental State Exam scores range from 0 to 30; TBI, traumatic brain injury; SD, standard deviation 
Table 3: Determinants of Voting in the Election (May 2007, November 2007 \& November 2008)

\begin{tabular}{|c|c|c|c|c|c|}
\hline VARIABLES & $\begin{array}{c}\text { Model } \\
1\end{array}$ & $\begin{array}{l}\text { Model } \\
2\end{array}$ & $\begin{array}{c}\text { Model } \\
3\end{array}$ & $\begin{array}{c}\text { Model } \\
4\end{array}$ & $\begin{array}{l}\text { Model } \\
5\end{array}$ \\
\hline \multirow{2}{*}{$\begin{array}{l}\text { Interviewed for November } \\
2008 \text { Election }\end{array}$} & 0.997 & 0.787 & 0.657 & 0.721 & 0.993 \\
\hline & $(0.813)$ & $(0.912)$ & $(0.847)$ & $(0.861)$ & $(0.873)$ \\
\hline \multirow{2}{*}{ Married } & $-2.604 * *$ & $-3.057 * *$ & $-2.338 * *$ & $-2.482 * *$ & $-2.751 * *$ \\
\hline & $(1.200)$ & $(1.358)$ & $(1.161)$ & $(1.160)$ & $(1.238)$ \\
\hline \multirow[t]{2}{*}{ Age } & $0.0694 *$ & $0.0726^{*}$ & $0.0592 *$ & $0.0618^{*}$ & $0.0760^{* *}$ \\
\hline & $(0.0363)$ & $(0.0402)$ & $(0.0355)$ & $(0.0357)$ & $(0.0379)$ \\
\hline \multirow{2}{*}{$\begin{array}{l}\text { Has a High School } \\
\text { Diploma }\end{array}$} & 1.058 & 1.638 & 1.578 & $1.870^{*}$ & 1.161 \\
\hline & $(1.168)$ & $(1.224)$ & $(1.126)$ & $(1.137)$ & $(1.205)$ \\
\hline \multirow[t]{2}{*}{ Internal Efficacy } & $0.228^{*}$ & 0.229 & 0.205 & 0.228 & 0.102 \\
\hline & $(0.138)$ & $(0.143)$ & $(0.135)$ & $(0.139)$ & $(0.131)$ \\
\hline \multirow[t]{2}{*}{ MMSE } & $0.161 *$ & & & & \\
\hline & $(0.0901)$ & & & & \\
\hline \multirow[t]{2}{*}{ CAT-V } & & $0.356^{* *}$ & & & \\
\hline & & $(0.181)$ & & & \\
\hline \multirow[t]{2}{*}{ Doe Standard Score } & & & $0.553 *$ & & \\
\hline & & & $(0.328)$ & & \\
\hline \multicolumn{6}{|l|}{ Extra-Doe: } \\
\hline \multirow[t]{2}{*}{ Reasoning Score } & & & & $0.556^{*}$ & \\
\hline & & & & $(0.288)$ & \\
\hline \multirow[t]{2}{*}{ Appreciation Score } & & & & & 0.801 \\
\hline & & & & & $(0.545)$ \\
\hline \multirow[t]{2}{*}{ Constant } & $-8.219 * *$ & $-8.220 * *$ & $-7.006^{* *}$ & $-6.171 * *$ & $-4.932 * *$ \\
\hline & $(3.390)$ & $(3.245)$ & $(2.891)$ & $(2.456)$ & $(2.223)$ \\
\hline Observations & 53 & 48 & 51 & 50 & 48 \\
\hline
\end{tabular}

Standard errors in parentheses; ${ }^{* * *} \mathrm{p}<0.01,{ }^{*} \mathrm{p}<0.05,{ }^{*} \mathrm{p}<0.1$ 


\section{Appendix}

\section{Competency Assessment Tool for Voting (CAT-V)}

"I'm going to ask you some questions about elections. This should take about five minutes. If you don't understand something I say or ask, please tell me and I will repeat it. Some of the questions may seem very simple to you, but don't worry about that. We are just looking for straightforward answers. Do you have any questions before we begin?"

\section{Understanding}

Imagine that two candidates are running for Governor of [fill in name: your state], and that today is Election Day in [fill in name: your state].

\section{Understands the nature of voting:}

What will the people of [fill in name: your state] do today to pick the next Governor?

Note to interviewer: If subject describes how he/she or people in general would choose between the two choices for governor (i.e. watch TV ads, listen to their campaign issues, etc.), ask:

Well that's how you might decide who you think should be governor. But how would you actually indicate your choice?

[Score of 2: Completely correct response, e.g., "They will go to the polls and vote." "Each person will cast his/her vote for one or the other." Score of 1: Ambiguous or partially correct response, e.g., "That's why we have Election Day." Score of 0: Incorrect or irrelevant response, e.g., "There's nothing you can do; the TV guy decides."]

\section{Understands the effect of voting:}

When the election for governor is over, how will it be decided who the winner is?

[Score of 2: Completely correct response, e.g., "The votes will be counted and the person with more votes will be the winner." Score of 1: Ambiguous or partially correct response, e.g., "By the numbers." Score of 0: Incorrect or irrelevant response, e.g., "It all depends on which sign they were born under."]

[Note that it is likely that some subjects will answer both of these questions in response to the first question. If so, they should be given a full score for each, and the second question may be omitted.]

\section{Choice}

[Hand subject a card with the information in the following paragraph in large print; allow subject to retain and consult this card for the remainder of the interview.]

Let me ask you to imagine the following about the two candidates who are running. Candidate A thinks the state should be doing more to provide health insurance to people who don't have it, and should be spending more money on schools. He is willing to raise taxes to get the money to do these things. Candidate B says the government should not provide health insurance but should make it easier for employers to offer it. He believes that the schools have enough money already but need tighter controls to make sure they use it properly. He is against raising taxes. 
Based on what I just told you, which candidate do you think you are more likely to vote for: A or B?

Note to interviewer: If subject can not choose a candidate or is vacillating, ask:

If you had to make a choice based on the information you have before you, who would you pick?

[Score of 2: Clearly indicates choice. Score of 1: Choice is ambiguous or vacillating, e.g., "I think I might go for the guy who doesn't like taxes, but I'm not sure because schools are important too." Score of 0: No choice is stated, e.g., "I don't know. I can never make up my mind."]

The following measures of reasoning and appreciation are not part of the Doe standard.

\section{$\underline{\text { Reasoning }}$}

Comparative reasoning:

If subject identifies a choice, ask: How is voting for [subject's choice] better than voting for [name of other candidate]? [Or if subject had no choice, ask: How might voting for Candidate A be better or worse than voting for Candidate B?]

[Score of 2: Identifies at least one comparative attribute in relation to the views of the two candidates, e.g., "Someone who really cares about health care would be a better governor." Score of 1: Ambiguous response, e.g., "Health care." Score of 0: Fails to mention a comparative attribute of the respective candidates, e.g., "I just think he's good." or "I can't see any difference"]

\section{Generating Consequences:}

If [subject's choice or Candidate A if subject had no choice] were elected governor in your state, how could that affect your life?

Note to interviewer: Probe for a reason if subject says it will not affect them.

[Score of 2: Identifies a consequence for his or her life, e.g., "I'd have more money to spend" or "I'd have better access to health care"; if sees no personal consequences, subject gives a coherent reason ("I'll be moving to another state soon." "I'll be dead in a year anyway.") Score of 1: Gives a vague consequence for his or her life, e.g., "Health." Score of 0: Does not give a consequence for his or her life or a reason for saying that there are no personally relevant consequences.]

\section{Appreciation}

Would you want to vote in the next election for governor of your state? If yes, why? If no, why not?

[Score of 2: Response based on reason that reflects reality of voting situation. E.g., if yes: "My doing that makes it more likely that the candidate I like will win." If no, "I don't care who wins"; "My one vote is unlikely to make much of a difference." Score of 1: Ambiguous response that partially reflects reality of voting situation. E.g., if yes: "It helps to run the country." If no, "They might not let me." Score of 0: Responses that fail to reflect reality of voting situation; confused or delusional responses. E.g., if yes: "The person I pick will win.” If no, "They never count my vote anyway."] 


\section{Appendix \\ Voting Efficacy Test \\ Participant ID:}

Date:

120

Please indicate how much you agree or disagree with these statements by checking the corresponding box:

\begin{tabular}{|c|c|c|c|c|c|c|}
\hline & $\begin{array}{c}\text { Agree } \\
\text { Strongly }\end{array}$ & $\begin{array}{c}\text { Agree } \\
\text { Somewhat }\end{array}$ & $\begin{array}{l}\text { Neither } \\
\text { Agree Nor } \\
\text { Disagree }\end{array}$ & $\begin{array}{l}\text { Disagree } \\
\text { Somewhat }\end{array}$ & $\begin{array}{l}\text { Disagree } \\
\text { Strongly }\end{array}$ & $\begin{array}{l}\text { Don't } \\
\text { Know }\end{array}$ \\
\hline $\begin{array}{l}\text { a. Public officials don't } \\
\text { care much what people like } \\
\text { me think. }\end{array}$ & & & & & & \\
\hline $\begin{array}{l}\text { b. people like me don't } \\
\text { have any say about what } \\
\text { the government does. }\end{array}$ & & & & & & \\
\hline $\begin{array}{l}\text { c. sometimes politics and } \\
\text { government seem so } \\
\text { complicated that a person } \\
\text { like me can't really } \\
\text { understand what's going } \\
\text { on. }\end{array}$ & & & & & & \\
\hline $\begin{array}{l}\text { d. I consider myself well- } \\
\text { qualified to participate in } \\
\text { politics. }\end{array}$ & & & & & & \\
\hline $\begin{array}{l}\text { e. I think that I am better } \\
\text { informed about politics } \\
\text { than most people }\end{array}$ & & & & & & \\
\hline $\begin{array}{l}\text { f. people with disabilities } \\
\text { have as much influence as } \\
\text { other groups in government } \\
\text { and public affairs. }\end{array}$ & & & & & & \\
\hline
\end{tabular}


g. Government officials treat people with

disabilities with as much respect and dignity as they treat members of other groups. 


\section{Appendix}

\section{Participant Characteristics}

Participant ID:

Date:

120

1. What is your gender?

__ Female___ Male

2.Do you consider yourself to be Hispanic or Latino?

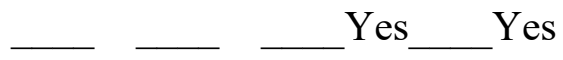

3. What race or ethnicity do you consider yourself?

White___ Asian__pacific islander___ Other (please provide):

Native American ___ Native American

4. What is your marital status?

Single (never married)

Divorced

Widowed

Married or Cohab. $>7 y$ rs

Separated Other

5. What is the highest level of education you have completed?

Some High

Diploma School Diploma

Some College

Some post-

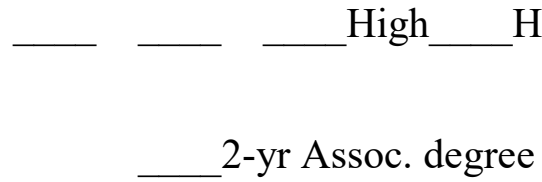

degree
High School 4-yr BA/BS degree

$\operatorname{grad} \_$MA degree___ PhD degree

6. What is the highest level of education anyone in your immediate family (parents and siblings) has completed? 
Some High

Diploma School Diploma

Some College

Some post-
- High $\_$-yr Assoc. degree
- _

$\operatorname{grad}$

MA

degree 4-yr BA/BS degree

High School

High

4-yr BA/BS degree

PhD degree 